\title{
MICROSYSTEMS BY BULK MICROMACHINING
}

\author{
M. Esashi \\ New Industry Creation Hatchery Center, Tohoku University, \\ Sendai, 980-8579, Japan, esashi@cc.mech.tohoku.ac.jp
}

\begin{abstract}
Deep RIE (Reactive Ion Etching) was developed not only for silicon but also for other materials and silicon microstructures made by the deep RIE was used as molds for making ceramic microstructures. Packaged micro mechanical sensors as pressure sensors and electrostatically levitating micro motors for gyroscope have been developed. Microprobes are fabricated for future data storage devices. Energy dissipation of resonating thin cantilever was studied for large $Q$ factor required for highly sensitive resonating sensors. Active catheters which move like snakes in blood vessel and sensors for the catheter have been studied for the purpose of minimal invasive medicine.
\end{abstract}

\section{INTRODUCTION}

Silicon bulk micromachining which is based on a silicon etching and a glass-silicon anodic bonding plays important roles to make microsystems. Three dimensional microfabrication of other functional materials as piezoelectric materials are also important to develop high performance microactuators, micro energy sources and so on. Vacuum sealing is required to prevent a viscous dumping for packaged micromechanical sensors. Extremely small structures as microprobe are required for high resolution, high sensitivity and quick response. Sophisticated microsystems which are made of many sensors, circuits and actuators are required for example for maintenance tools used in a narrow space. Developments for these requirements will be described.

\section{DEEP RIE PROCESSES AND THEIR APPLICATIONS}

Deep RIE of silicon has been studied[1,2] and applied for resonating gyroscopes[3] and other devices. Isotropic gas etching of silicon using $\mathrm{XeF}_{2}$ gas was also studied and combined with the deep RIE for precise micromachining[4]. Deep RIE processes of Pyrex glass[5], quartz[6,7], PZT (lead zirconium titanate)[7] and SiC (silicon carbide)[8] using thick nickel as a mask has been also studied. Pyrex glass could be etched through the thickness of $200 \mu \mathrm{m}$. Vertical etch profile was obtained when the mask opening is narrower than $20 \mu \mathrm{m}$ because the deposition of non volatile products on the side wall is reduced[5]. The hole made in a Pyrex glass can be used for an electrical feedthrough from a packaged sensor[9].

Novel process for ceramic microstructures has been developed. A micromachined silicon wafer is used as a mould for sintering ceramics as PZT[10] and SiC[11]. The silicon mould is formed by the deep RIE and is cast with slurry. Ceramic microstructures are obtained by a hot isotropic pressing and finally the silicon mold is etched out[10]. SiC micro turbine was fabricated by micro-reaction sintering $\left(1700^{\circ} \mathrm{C}, 100 \mathrm{MPa}\right)$ using silicon as a mould[11].

Silicon micro air turbine for rotating a wire grid polarizer has been fabricated using the deep RIE of silicon. This device is a polalization modulator needed for surface infrared adsorption spectroscopy. The structure is shown in Fig.1. Air bearing was used and the rotational speed of $10000 \mathrm{rpm}$ was achieved [12]. Micro power generators made of $\mathrm{SiC}$ micro air turbine are under development using the deep RIE and the micro-reaction sintering mentioned above.

\section{PACKAGED MICROMECHANICAL SENSORS}

Small size packaged mechanical sensors as integrated capacitive pressure sensor have been developed[13]. A force balancing capacitive pressure sensor was developed for vacuum measurement[14]. As shown in Fig.2 a thin diaphragm and a vacuum cavity are formed in an anodically bonded glass-silicon-glass structure. NEG (Non Evaporable Getter) is put inside the cavity to absorb the oxygen gas generated during the anodic bonding process[15]. The sensor covers a wide pressure range $(0.1 \mathrm{~Pa}-1000 \mathrm{~Pa})$ by measuring the servo voltage.

An electrostatically levitating micromotor shown in Fig.3 has been developed for high precision inertia measurement system which operates as two-axis gyroscope and also three-axis accelerometer [16]. The rotor is 

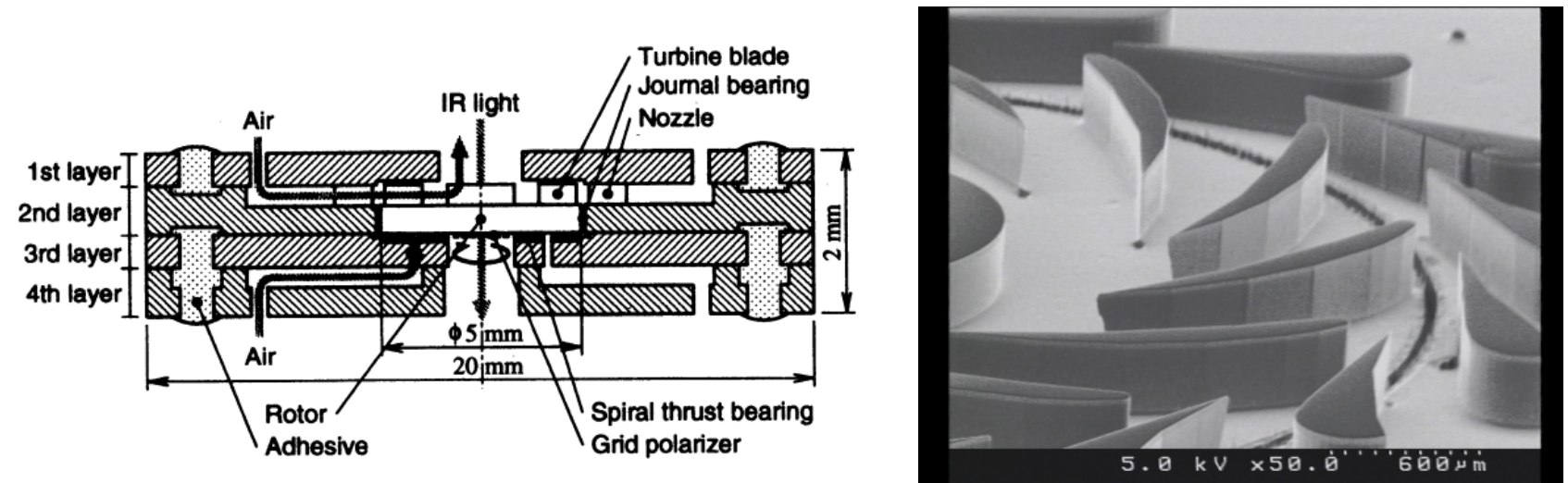

Fig.1 Silicon micro air turbine

fabricated using the deep RIE of silicon. The levitation is performed by force balancing in all direction using a capacitive displacement sensing and an electrostatic actuation[17]. A silicon rotor is packaged in a vacuum cavity and the gaps between the silicon rotor and the electrodes on the glasses are $5 \mu \mathrm{m}$. The levitation and rotation $(2000 \mathrm{rpm} / \mathrm{min})$ were successfully demonstrated.

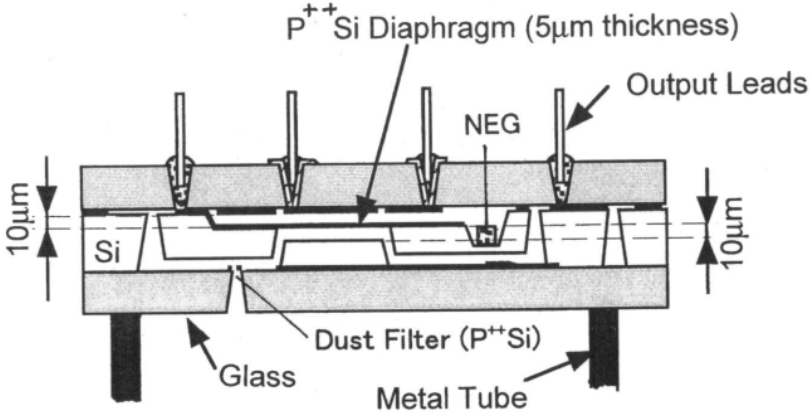

Fig.2 Force balancing silicon diaphragm pressure (vacuum) sensor

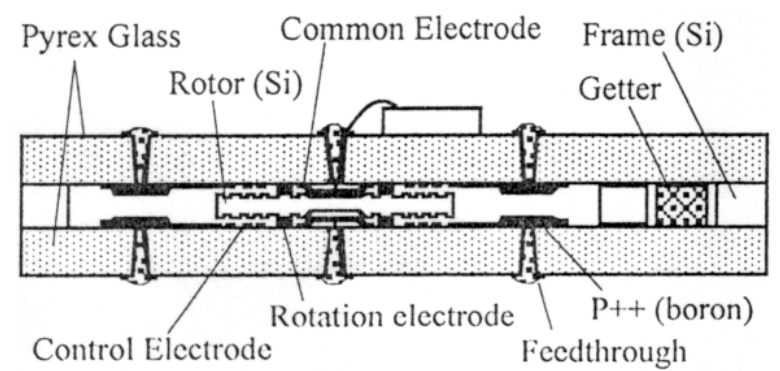

Fig.3 Electrostatically levitating micromotor

\section{MICRO PROBES}

Microprobes for SPM (Scanning Probe Microscope) and high-density data storage device have been developed using micromachined cantilevers. Capacitive AFM (Atomic Force Microscope) probe[18], heater integrated probe[19], capacitive NSOM (Near-field Scanning Optical Microscope) /AFM probe[20] and electro-magnetically self-actuating AFM probe array have been studied[21]. The capacitive NSOM/AFM probe is shown in Fig.4. The probe has an advantage of large throughput of the light intensity and farther a coaxial structure could be fabricated at the tip[22].

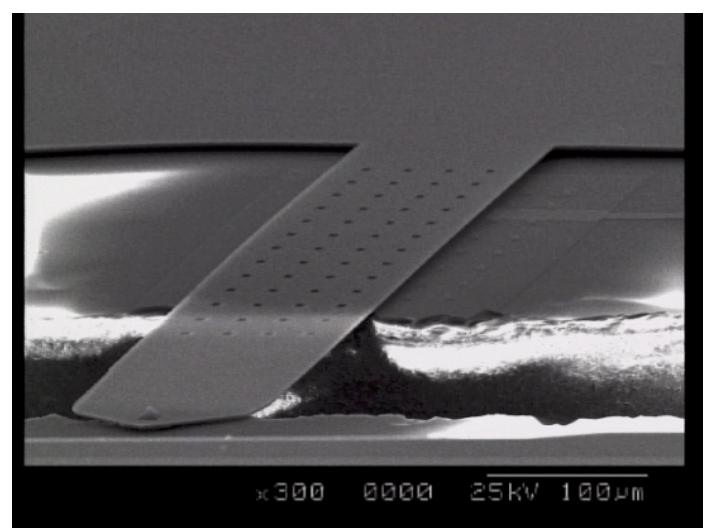

(a)

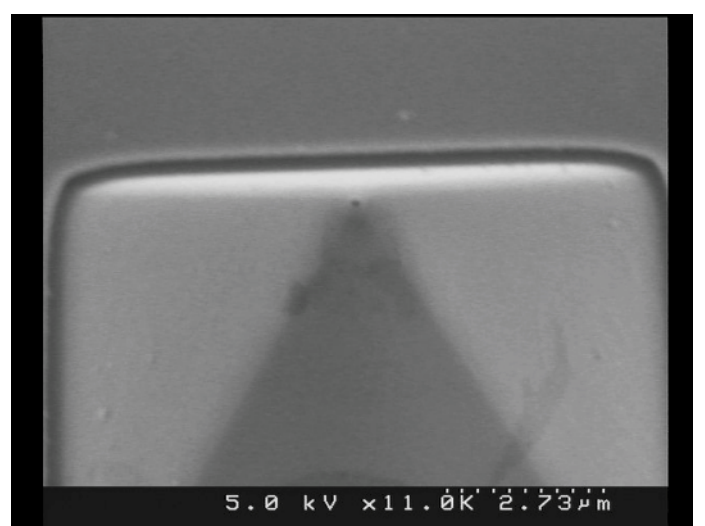

(b)

Fig.4 Capacitive NSOM/AFM probe (a) and the tip with a $20 \mathrm{~nm}$ opening (b) 


\section{ENERGY DISSIPATION OF RESONATING THIN CANTILEVER}

Thin silicon beams can be used as resonating sensors. Quick response and high sensitivity are achieved by increasing the resonant frequency and Q (quality factor) respectively. The scaling down leads to the high resonant frequency, while the $\mathrm{Q}$ is influenced by energy dissipation[23]. Surface loss dominates the energy loss if thin single crystal silicon cantilever is resonated in high vacuum. After removing surface oxide by heating in ultra high vacuum(UHV) Q factor higher than 200000 was obtained in UHV. It was also found hydrogen termination of the surface leads to reduced surface loss [23].

\section{ACTIVE CATHETERS AND RELATED SENSORS}

Multi-link active catheters which move like a snake in blood vessel have been developed for navigation control in minimal invasive diagnosis and therapy[24,25,26]. Distributed shape memory alloy (SMA) coils are utilized as actuators for movement in multi-degrees of freedom. To minimize the number of lead wires integrated circuits for communication and control with three common lead wires are incorporated within each links as shown in Fig.5[25]. CMOS integrated circuit chips which have flexible polyimide-based interconnect leads were developed to minimize the assembly work. Active catheters which have bending, torsional, extending and stiffness control functions as shown in Fig.6 were developed[26]. A SMA coil and a stailless steel liner coil are connected nickel electroplating and acrylic resin electrodeposition. This novel method makes low cost batch assembly and small outer diameter $(1.4 \mathrm{~mm})$ possible.

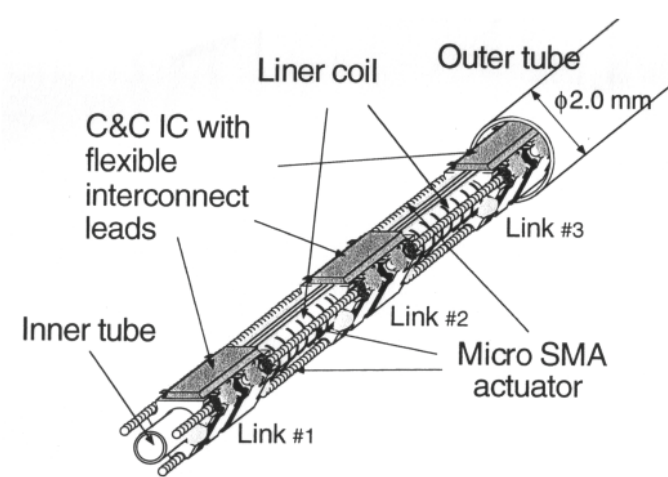

Fig.5 Active catheter which has integrated communication and control (C\&C) circuit.

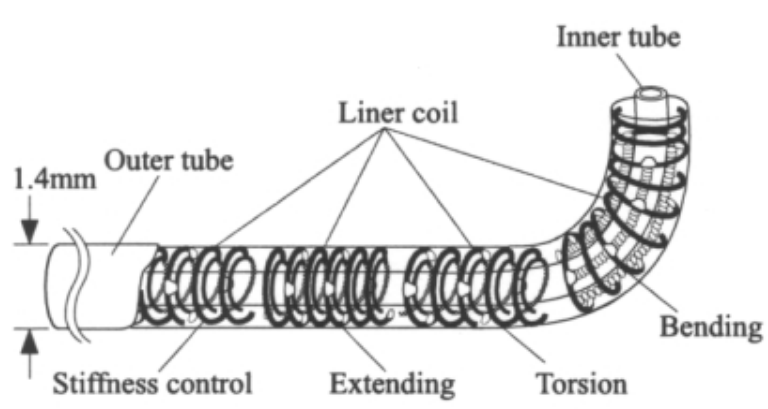

Fig.6 Active catheter which can not only be bent but also twisted and extended

Small diameter $(125 \mu \mathrm{m} \phi)$ fiber optic pressure sensor shown in Fig.7 has been developed for catheter use[27]. A thin diaphragm is formed at the end of an optical fiber and the deformation by a pressure is detected interferometrically. The diaphragm is formed on a silicon wafer and the wafer is etched by the deep RIE to make silicon rods. The silicon rod is bonded to the fiber end by heating in a glass tube. Finally silicon is etched out using $\mathrm{XeF}_{2}$ gas.

An forward-looking ultrasonic imager has been developed (Fig.8). Piezoelectric PZT ceramic transducer array was made at the end of a catheter. Improved 1-3 composite piezoelectric transducer, built-in integrated circuit and micro relay for multiplexing the drive pulse are being developed as an integrated ultrasonic imager at the end of catheter [28].

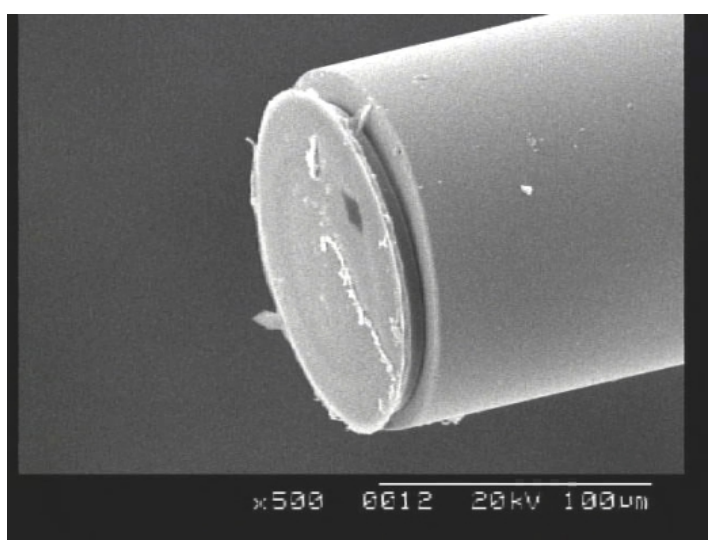

Fig.7 Fiber optic pressure sensor

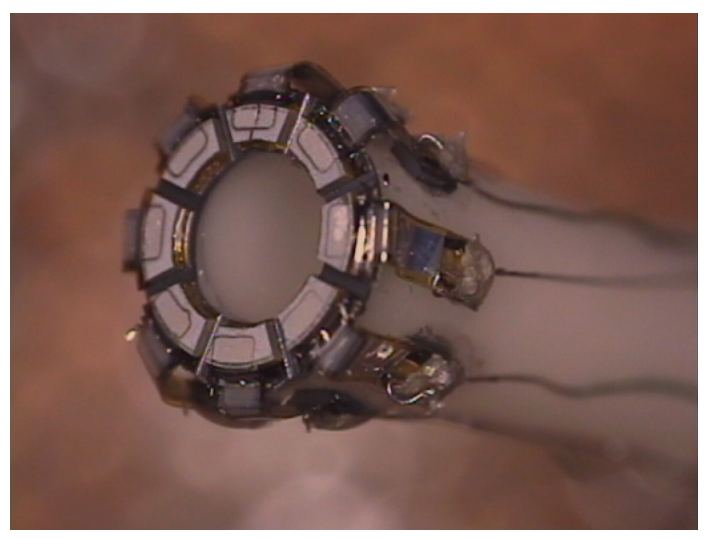

Fig.8 Ultrasonic imager at the end of a catheter 


\section{REFERENCES}

1) M.Takinami, K.Minami and M.Esashi," High-Speed Directional Low-Temperature Dry Etching for Bulk Silicon Micromachining”, Technical Digest of the 11th Sensor Symposium, pp.15-18, 1992

2) S.Kong, K.Minami and M.Esashi, "Fabrication of Reactive Ion Etching System for Deep Silicon Machining", The Trans. of the IEE of Japan, 117-E, pp.10-19, 1997

3) J.Choi, K.Minami and M.Esashi, "Application of Deep Reactive Ion Etching for Silicon Angular Rate Sensor", Microsystem Technologies, 2, pp.186-190, 1996

4) R.Toda, K.Minami and M.Esashi, "Thin-Beam Bulk Micromachining Based on RIE and Xenon Difluoride Silicon Etching", Sensors and Actuators, A66, pp.268-272, 1998

5) X.Li, T.Abe and M.Esashi,'Deep Reactive Ion Etching of Pyrex Glass", Proc. of MEMS'2000, pp. 271-276, 2000

6) T.Abe and M.Esashi,"One-chip Multichannel Quartz Crystal Microbalance (QCM) Fabricated by Deep RIE", Sensors and Actuators, A82, pp.139-143, 2000

7) T.Abe, K.Wakabayashi, X.Li and M.Esashi,'Deep RIE System for Hard Etching Materials”, Technical Digest of the 17th Sensor Symposium, pp.225-258, 2000

8) S.Tanaka and M.Esashi,"Deep Reactive Ion Etching of Sintered Silicon Carbide"(in Japanese), Late News of the 17th Sensor Symposium",p.106, 2000

9) X.Li, Y.Liu, T.Abe and M.Esashi,"Application of Pyrex Glass Deep Reactive Ion Etching to Electrical Feedthrough", Late News of the 17th Sensor Symposium",p.107, 2000

10) S.Wang, J.F.Li, R.Watanabe and M.Esashi,"Fabrication of Lead Zirconate Titanate Microrods for 1-3 Piezocomposites Using Hot Isostatic Pressing with Silicon Molds", J. American Ceramic Soc.,82,pp.213-215, 1999

11) S.Sugimoto, S.Tanaka, J.F.Li, R.Watanabe and M.Esashi."Silicon Carbide Micro-reaction-sintering Using a Multilayer Silicon Mold", Proc. of MEMS'2000, pp. 775-780, 2000

12) M.Esashi, "Encapsulated Micro Mechanical Sensors", Microsystem Technologies, 1, pp.2-9,1994

13) M.Esashi, S.Sugiyama, K.Ikeda, Y.Wang and H.Miyashita, "Vacuum-Sealed Silicon Micromachined Pressure Sensors", Proceedings of the IEEE, 86, pp.1627-1639, 1998

14) H.Henmi, S.Shoji, Y.Shoji, K.Yoshimi and M.Esashi, "Vacuum Packaging for Microsensors by Glass-Silicon Anodic Bonding", Sensors and Actuators, A43, pp.243-248, 1994

15) K.Fukatsu, T.Murakoshi and M.Esashi, "Electrostatically Levitated Micro Motor for Inertia Measurement System", Digest of Technical Papers, Transducers'99, pp.1558-1561, 1999

16) K.Jono, M.Hashimoto and M.Esashi, "An Electrostatic Servo-type Three-axis Silicon Accelero-meter", Measurement Science Tech., 6, pp.11-15, 1994

17) S.Tanaka, M.Hara and M.Esashi,"Air-Turbine-Driven Micro-Polarization Modulator for Fourier Transform Infrared Spectroscopy", Technical Digest of the 17th Sensor Symposium, pp.29-32, 2000

18) Y.Shiba, T.Ono, K.Minami and M.Esashi, "Capacitive AFM Probe for High Speed Imaging", The Transaction of The IEE of Japan,118-E, pp.647-651, 1998

19) N.Takimura, D.W.Lee, M.N.Phan, T.Ono and M.Esashi, "Heater Integarated Micro Probe for High-Density Data Storage", Technical Digest of the 17th Sensor Symposium, pp.423-426, 2000

20) P.N.Minh, T.Ono and M.Esashi, "Nonuniform Silicon Oxidation and Application for the Fabrication of Aperture for Near-field Scanning Optical Microscopy", Applied Physics Letters, 75, pp.4076-4078, 1999

21) D.W.Lee, T.Ono and M.Esashi,"Surface Imaging with Electro-Magnetically Self Actuating AFM Probe", Technical Digest of the 17th Sensor Symposium, pp.433-436, 2000

22) P.N.Minh, T.Ono and M.Esashi,"Preliminary Result on Fabrication of Coaxial Tip for High Throughput Scanning Optical Probe", Late News of the 17th Sensor Symposium",p.108, 2000

23) J.Yang, T.Ono and M.Esashi, " Dominated Energy Dissipation in Ultra Thin Single Crystal Silicon Cantilever : Surface Loss", Proc. of the MEMS'2000, pp.235-240, 2000

24) G.Lim, K.Park, M.Sugihara, K.Minami and M.Esashi, "Future of Active Catheters", Sensors and Actuators, A56, pp.113-121, 1996

25) K.-T.Park and M.Esashi, "A Multilink Active Catheter with Polyimide-Based Integrated CMOS Interface Circuits", J. of Microelectromechanical Systems, 8, pp.349-357, 1999

26) Y.Haga, M.Esashi and S.Maeda, "Bending, Torsional and Extending Active Catheter Assembled Using Electroplating", Proc. of MEMS'2000, pp.181-186, 2000

27) T.Katsumata, Y.Haga, K.Minami and M.Esashi, "Micromachined 125• m Diameter Ultra Miniature FiberOptic Pressure Sensor for Catheter", The Transaction of The IEE of Japan,120-E, pp.58-63, 2000

28) M.Nishio, K.Tani, Y.Haga and M.Esashi, "Preliminary Study of Integrated Ultrasonic Probe for ForwardLooking in Blood Vessel", Technical Digest of the 17th Sensor Symposium, pp. 55-60, 2000 